\title{
On the Productive Efficiency of Australian Businesses: Firm Size and Age Class Effects
}

\author{
Marc Cowling \\ Brighton Business School \\ University of Brighton \\ Brighton BN2 4AT \\ UK \\ E-mail: M.Cowling2@brighton.ac.uk \\ George Tanewski \\ Deakin Business School \\ Deakin University \\ Burwood VIC 3125 \\ Australia \\ E-mail: g.tanewski@deakin.edu.au
}

\begin{abstract}
After 26 years of growth, the Australian economy is beginning to show signs of stress and declining productivity. In this paper we consider aspects of productive efficiency using an Australian business population dataset. Using a production function approach several key findings are uncovered. Firstly, decreasing-returns-to-scale are identified as a significant feature of the Australian business sector. This implies that not all firm growth will lead to productivity gains. Secondly, there are significant differences in the way value added is created between small and large firms. In the largest $25 \%$ of firms the capital contribution to value added is four times that of the smallest $25 \%$ of firms. Thirdly, efficiency follows an inverted ' $U$ ' shaped in firm age with the youngest (0-2 years) and oldest ( $>9$ years) firms' being less productive than the middle $50 \%$ of firms. Fourthly, there are also huge industry sector variations in productivity. In particular, financial services appears to be the most productively efficient sector in the Australian economy and mining the least efficient.
\end{abstract}




\section{Introduction}

In 2017, Australia became the world record holder for the longest uninterrupted period of GDP growth at 103 quarters or 26 years. It is the $12^{\text {th }}$ largest economy in the world, and has the eighth largest reserves of natural resources. Until very recently the country had experienced two decades of growing prosperity fuelled by booming mineral prices and demand from China. Yet this sustained growth in incomes masked some negative underlying economic trends such as a significant decline in the trend rate of GDP growth since 1999, and a reversal of the 1993-2008 downward trend in unemployment which now stands at its highest level since 2003. More importantly, growth in productivity is at the same rate now as it was in 1978 , despite the $4^{\text {th }}$ industrial revolution and huge advances in technology and skills.

In this paper we argue that, in the light of these negative economic trends, that there is a need to understand more about productivity in Australia, with a particular emphasis on the SME sector which constitutes $99.6 \%$ out of the total business stock of 954,367 . This is particularly apposite as within the economy there are industry sectors that have experienced economic downturns and rising unemployment. Understanding how value added is created from physical capital and labour across firm size classes and industries is fundamental to developing a more nuanced picture of why the Australian economy may have reached a turning point. This is supported by new evidence that Australian businesses have been going backwards since 2007 on several key measures such as product differentiation, profitability, exporting, training, and investment in IT (IPA, 2015).

In this paper we provide evidence on the determination of productivity across the Australian private business sector. Specifically, we focus on productivity differences across size, age, and industry sector classes of firms and seek to identify how the responsiveness of output with respect to labour and capital varies across different 'types' of firms. We also consider variations in what is termed the 'state of technology', which relates to the adoption and understanding of common technologies. In 
essence, we are seeking to understand how value added is created, what combinations of labour and capital are combined to create value added, the role of technology, and how all of these issues vary across different 'types' or classes of business.

This is important for two reasons. Firstly, previous empirical studies have established that there are, "enormous and persistent measured productivity differences across producers, even in narrowly defined industries" (Syverson, 2011: 326). The scale of measured productivity differences across firms is often large, to the extent that the average difference in total factor productivity (TFP) between the top $10 \%$ and the bottom $10 \%$ of firms at the 4-digit level in a US manufacturing industry study (Syverson, 2004) was estimated to be a factor of 2 . This implies that the top $10 \%$ of firms, using the same inputs to production, managed to produce twice as much output as the bottom $10 \%$ of firms. In a similar study for China and India, Klenow and Hsieh (2009) found that these top10\%bottom $10 \%$ productivity could be even larger with a factor of 5:1. Importantly, there is common agreement across studies and time that when productivity differences are identified they exhibit a significant degree of persistence (Abraham and White, 2006; Foster, Haltiwanger, and Syverson, 2008). This body of empirical evidence highlighting the considerable variations in productivity not only across firms, but within industries, is also consistent with a recent paper (Pozzi and Schivardi, 2015) which formally dropped the assumption that all firms output within a given industry is essentially viewed by customers as being homogenous. Thus we are able to tease out evidence relating to firm class heterogeneity in the sense that firms with comparable factor inputs, even within the same industry sector, have differing abilities to create value through their production processes.

Secondly, and extrapolating to the wider economy, increases in productivity are fundamentally linked to sustaining growth in incomes and wealth. Hence understanding, in an Australian context, 
the absolute level of productivity in the private business sector, how it is determined, and how much variation across different classes of firms is fundamental to developing our understanding of the productive potential of the major contributor to overall Australian GDP and per capita incomes. This is particularly important, as is the case in most economies, given the overwhelming numerical dominance of the SME sector, and the high share of very young firms in the business stock. Both smaller and younger firms we might $a$ priori expect to be operating at below their industry level minimum efficient scale (MES) due to constraints in factor markets, particularly in respect of access to skilled workers (Freel, 2005; Atkinson and Storey, 2016) and external capital (Stiglitz and Weiss, 1981).

The rest of the paper is organised as follows: In Section 2 we review some key literature relating to the organisation of production and differences in productive efficiency, focusing in particular on how firm size and age effects both. We then describe our data and methodology in Section 3 with an initial test relating to the precise specification of the production function. In Section 4 we present our main findings and augmented production function models along with a discussion of key findings. We conclude in Section 5.

\section{Literature Review}

Here we initially consider the small firm literature relating to the organisation of production and the relative productive efficiency of firms. This is important as empirical works highlight some substantive differences in the way factor inputs, resources are combined to create value added in SMEs, the relative returns to the core factor inputs, capital and labour, and the potential for many SMEs to operate at a scale below the minimum efficient level for their industry. It also relates to potential constraints in both capital and labour markets which are likely to impact disproportionately 
on smaller firms who lack access to primary equity markets and often face rationing in debt markets, and also in respect of access to primary labour markets for skilled workers. Then we consider the empirical literature relating to broader studies covering SMEs and larger firms. Both of these empirical literatures on productivity and efficiency provide context for our study which, although covering all size classes of business, is dominated by SMEs.

\subsection{Age class effects}

The first point of note in this respect is that there is a fragmented and under-developed empirical literature explicitly concerned with productive or technical efficiency in smaller firms. This was raised in a World Bank Research Observatory volume by Li and Rama (2015) who viewed this as an important omission given that small businesses typically represented in excess of $90 \%$ of the total stock of firms and more than $50 \%$ of total output and employment. Their study examined the relationships between growth, job creation and total factor productivity and explored the dynamic processes by which growth occurs through increased labour productivity and the broader creative destruction first outlined by Schumpeter (1934). Here more productive jobs are created and less productive jobs are destroyed over time.

Underpinning their work was a robust body of evidence that small, and particularly, younger firms accounted for a high, and disproportionate, share of net job creation (Neumark, Wall, and Zhang, 2009; Haltiwanger, Jamin, and Miranda, 2010), particularly a tiny subset of young firms termed 'gazelles' (Acs and Mueller, 2008; Coad, Daunfeldt, Hölzl, W, Johansson, and Nightingale, 2014). But they also noted two additional empirical facts. Firstly, that productivity varies markedly across firms, and secondly, that aggregate productivity growth is driven by within-firm dynamics, but also by reallocation between firms. This latter aspect in particular allows for the entry of new firms 
(primarily small firms) and the exit of existing firms. And this implies that the dynamics of small and young firms is fundamental to understanding productivity, as most firms start small and die small and young (Bartelsman, Scarpetta, and Schivardi, 2005; Siepel, Cowling, and Coad, 2017). In line with the literature on creative destruction, where younger, and typically smaller, firms enter markets to replace older, less efficient firms we propose the following hypothesis:

H1: Younger classes of firm will exhibit increasing returns-to-scale as they gain market share from older firms and seek to move towards the MES (minimum efficient scale) of production

\subsection{Firm size class effects}

The small firm productivity and efficiency work, partly due to its sparsity, but perhaps more to do with large and significant variations in the nature of the data sets used, has not really established a consensus on how production is organised in smaller firms and their relative efficiency as an economic agent. An empirical study of technical efficiency in Shanghai manufacturing (Chow and Fung, 1997) found the interesting result that technical efficiency was ' $U$ ' shaped in firm size. But this is contrary to the Bento and Restuccia (2014) in their multi-country manufacturing study which identified size-dependent distortions (e.g tax and regulatory exemptions for smaller firms) as an important feature of the observed firm size distribution, but found that this resulted in an inefficient allocation of resources and a sub-optimal concentration of inefficient firms at the threshold. More generally, there was a monotonic relationship between firm size and total factor productivity (TFP) across firm size deciles. And this distorting effect was also established in the context of sizedependent financial frictions as capital tends to flow disproportionately to firms with higher net worth (Coco, 2000; Cowling, 2001) which represents a misallocation of resources if good projects (and more talented entrepreneurs) are more widely distributed than net worth (Gopinath, Kalemli- 
Özcan, Karabarbounis, Villegas-Sanchez, 2017; Wang, 2010). This positive firm size effect is also confirmed in a recent study of French and Dutch firms by Raymond et al (2015) using a short panel of Community Innovation Survey data. Their findings showed that there were large and significant productivity changes as firm size class increased from small to medium-sized to large and through to very large firms. Importantly, their study also showed, along with many others, that productivity exhibited a strong degree of persistence. In short, the most productive firms today are more likely to be the most productive firms tomorrow, although Antonelli et al (2016), using data for Italian manufacturing industries, found that persistence is largely unrelated to firm size. In line with the majority, but not all, empirical studies relating firm size and productivity, we propose a second hypothesis:

H2: Productivity is increasing in size class of business

\subsection{A differentiated role for SMEs}

The Antonelli et al (2016)study is particularly important for developing our thinking around SMEs and productivity as the authors not only argue that different size classes of firm have a very different role in understanding productivity and how value added is created, but also embed the theory of creative destruction into their model. They also argue that SMEs are particularly effective in not only technological adoption, but more importantly in adapting existing technologies and knowledge to particular local market conditions. This is largely supported by a UK study (Cowling, 2003) which considered the relative contributions of entrepreneurial, managerial, and normal labour to productivity. This study found that the majority of smaller firms faced increasing returns-to-scale, and important there were very large and positive returns to the human capital of the top management and ownership team, over and above that derived from 'normal' labour. This human 
capital theme was picked up by Bloom and Van Reenen (2007) in an illuminating multi-country productivity study which matched top management team survey data relating to operational strategies to standard production function data. Whilst the study only focused on medium-size firms, it implicitly understood that talented managers would be more likely to adopt 'best-practice' strategies and that these superior strategic choices would feed through into observed productivity differences. Aside from establishing that more talented managers are associated with more productive firms, they also found that market competition drives the search for better strategic options. In short, this body of work formally establishes, and provides an evidence base, a role for the entrepreneur and the top strategic decision-makers in smaller firms which extends beyond the typical labour inputs measures adopted in productivity studies. This gives rise to our third hypothesis:

H3: There will be a negative relationship between the prevailing 'state of technology' and firm size and age classes

\subsection{Factor input combinations}

It is also interesting to relate factor markets to how firms organise their production. In relation to capital markets there is a voluminous theoretical and empirical literature setting out the conditions under which credit (and equity) rationing might occur (Stiglitz and Weiss, 1981; Parker and Van Praag, 2006). Importantly, due to information based problems, where capital market constraints exist, there are more likely to be imposed upon smaller and younger firms (Blinder, 1987; Cowling, 2010). As a consequence of capital market rationing, smaller and younger firms would be more likely to adopt labour intensive production techniques and combinations. And faced with capital rationing, the relative productivity effects of relaxing this constraint would be greater for an additional unit of 
capital compared to labour (Evans and Jovanovic, 1989). We can relate this capital constraints literature to a further hypothesis:

H4: Smaller (larger) classes of firm will adopt more labour (capital) intensive modes of production

However, this focus on capital rationing and its potential impact on how production is organised in firms of different size classes, fails to consider the fact that smaller firms may also be constrained in labour markets, particularly primary labour markets for skilled workers. There is strong and consistent empirical evidence that smaller firms pay lower wages, more tenuous contracts, and offer fewer pecuniary and non-pecuniary benefits (Acs, 1992; Brown and Medoff, 1990). Further, the costs of hiring skilled workers as well as the time spent in job search, may reduce the attractiveness of protracted search for new hires leading smaller firms to draw their labour from local (secondary) labour markets. In a broader sense, we might expect that over time workers become more efficient through job specific learning-by-doing (Arkolakis, Papageorgiou, and Timoshenko, 2015; Evans, 1987). There is also a more direct learning-by-doing aspect in that workers become more efficient as they 'learn' how to operate their plant \& machinery more effectively. Here the marginal productivity of labour increases through learning, even with a constant capital stock. But there is also an important, and contrary, aspect of learning that has been considered more recently in the productivity literature relating to knowledge depreciation (Boone, Ganeshan, and Hicks, 2008; Li, and Rajagopalan, 1998). Here learning over the firms (and workers) life-cycle is increasing initially and then diminishing in later life. 


\subsection{The wider context}

But setting this small body of production function and efficiency work aside, it is evident, for many good reasons, particularly availability of data, that the overwhelming majority of empirical work relating to production functions and total factor productivity relates to large firms (see for example work from the 1990s by Wadhwani and Wall, 1990, and Nickell, 1996, and very recent works by Montresor and Vezzani, 2015, who examined the effects of R\&D investment across deciles on productivity, Leon-Ledesma, McAdam, and Willman, 2015, who studied factor substitution and the CES production function for the US, and Beugelsdijk, Klasing, and Milionis, 2017, who looked at regional persistence in TFP across Europe). The scale and scope of the large firm, industry specific, city and regional, and cross-country body of work on productivity TFP, and growth is immense, but still new angles and insights are spurring new research efforts. In this paper, as we are using data derived from (literally) the ATO Tax Returns for the entire registered business population of Australia, we are able to add new insights simply because we have full coverage of all size and age classes of firm. We proceed by describing the data available to use and discuss some of the more technical considerations around estimating production functions.

Whilst we have proposed four specific hypotheses to test against our data, and establish how firms organise their production, and create value added, we pose on overarching research question that motivates our study and clearly links the economic theory of production (and costs curves) and the economics of small business. Our overarching research question is:

$R Q:$ Is it the case, as theory predicts, that smaller and younger firms should be disadvantaged due to their scale and youth in creating value added? 
We set this broad question against its obvious counterpart that smaller and younger businesses are run by dynamic entrepreneurs who are more capable of combining resources and technology in new combinations to create more value added.

\section{Data and Methodology}

In total, the Australian business sector in 2014-15 contains 954,367 businesses who file annual accounts to the Australian Taxation Office (ATO). The ATO Company Tax Return collects the following for each company;

- Company details and tax registration code

- Status defined by legal form but additional categories for (a) Ceased business (code E2), and, (b) Commenced business (code E3).

- Calculation of total profit or loss including income and expenses statements

- Reconciliation to taxable income and loss

- Financial statement

- Capital allowances

- Calculation statement of tax

We note here that the ATO reporting identifies two interesting classes of business: E2 Ceased business - a business that was operating at some point in the tax year, but has subsequently ceased trading, and; E3 Commenced business - a business that was not operating in the prior tax year but commenced operations at some point in this tax year. In this sense we have data for all businesses that were operating at some point in the tax year 2014-15. In terms of the composition of the business population, the industry sector distribution of businesses in shown in Fig 1 . Here we observe that K: Financial and Insurance Services is the single largest industry sector in terms of number of businesses with a total of 174,385 businesses operating. Other industry sectors with large 
numbers of businesses include D: Electricity, Gas, Water, and Waste, 146,978 businesses; A: Agriculture, Forestry, and Fishing, 123,341 businesses, and; C: Manufacturing, with 113,456 businesses. Industry sectors with low numbers of businesses include: I: Transport, Postal, and Warehousing, with 3,431 businesses, and; F: Wholesale Trade, with 7,045 businesses. Unfortunately, the ATO data available to us does not contain a geographical identifier as it is grouped into classes of business.

Fig 1: Numbers of Businesses by Industry Sector

K.Financial and Insurance Service D.Electricity, Gas, Water and Waste

A.Agriculture, Forestry and Fishing

C.Manufacturing J.Information Media and... P.Education and Training O.Public Administration and Safety

E.Construction

G.Retail Trade

S.Other Services

R.Arts and Recreation Services H.Accommodation and Food Services

Q.Health Care and Social Assistance N.Administrative and Support Services

M.Professional, Scientific and Te B.Mining

L.Rental, Hiring and Real Estate F.Wholesale Trade I.Transport, Postal and Warehousing

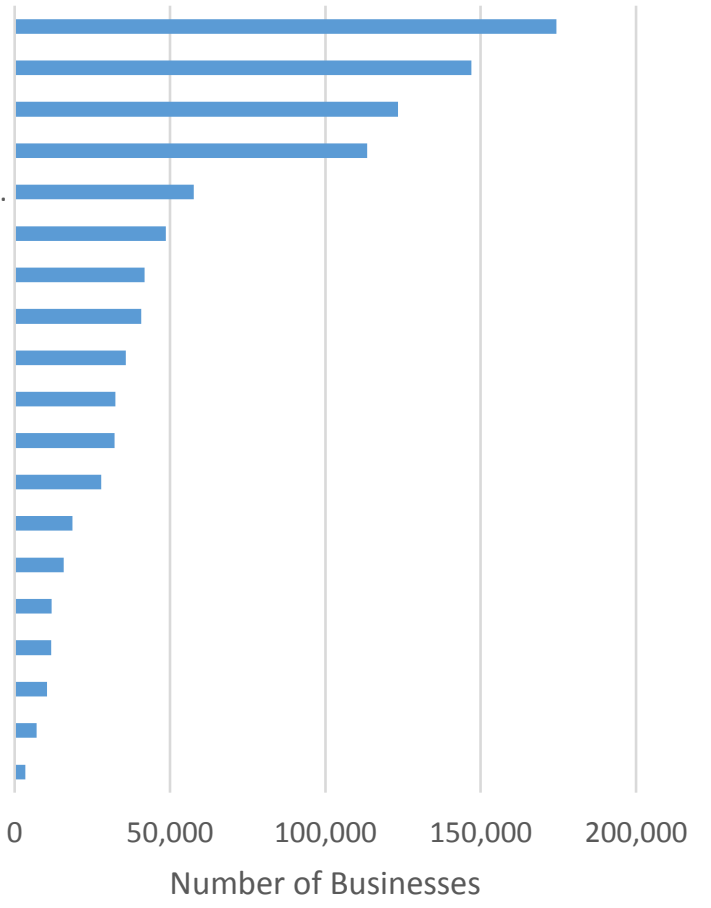

In respect of the firm age class distribution (Fig 2), we observe that $47.8 \%$ of the total registered business stock, 456,201 businesses, have been trading for at least ten years. But, in contrast, 22.3\%, 213,292 businesses are under the age of three. Thus there is a non-trivial representation of young businesses in the population. As our data is effectively an annual business census, we capture all firms that traded in this tax year, 2014-15, as even businesses that ceased trading, as well as those that entered, are in the population and hence the data set. An interesting feature of the age 
distribution is the relatively hollow middle which contains just under $30 \%, 284,874$ businesses, of the total population.

Fig 2: Firm Age Class Distribution

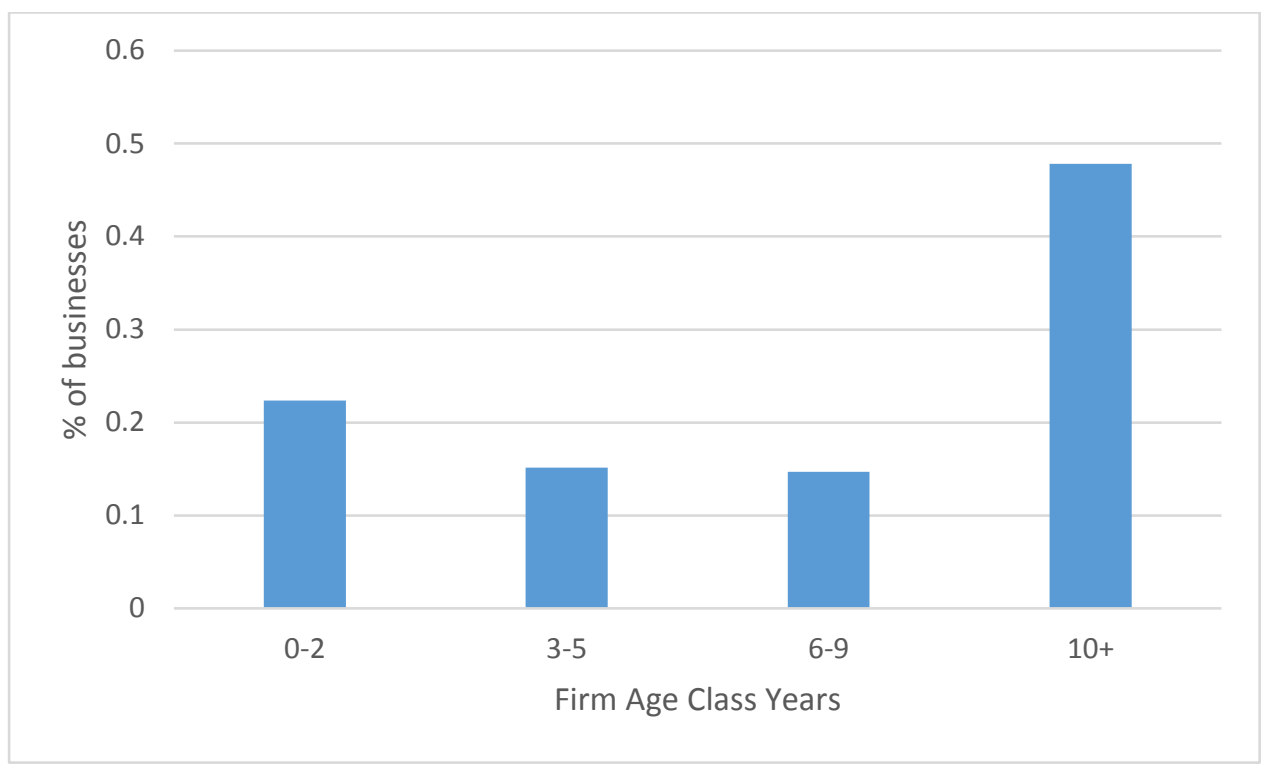

Fig 3 shows the firm size distribution as defined by sales where small business classes have up to AUD\$2m, mediums-sized firms AUD\$2-10m, and large firms >AUD\$10m. We exclude 131,225 lossmaking businesses. Small firms dominate the business population with $90.27 \%$ of the total stock. Medium-sized firms represent a further $7.67 \%$, with the large firm share at $2.06 \%$. This proportional representation is consistent with comparable shares in developed economies and emphasises the numerical dominance of SMEs in the Australian economy. 
Fig 3: Firm size class distribution

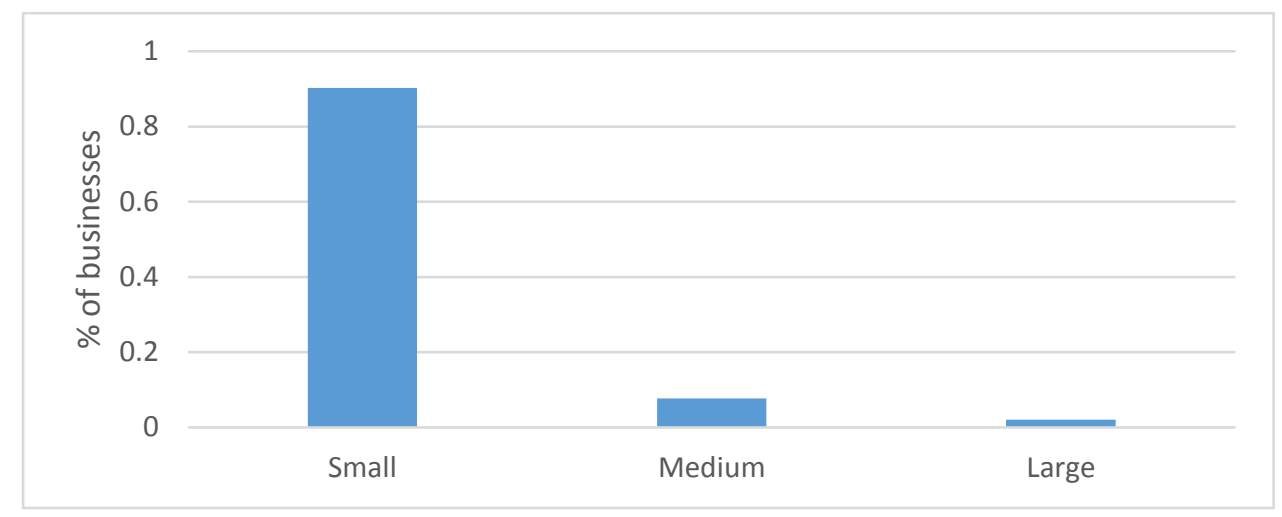

Then we present the basic sample statistics relevant to our estimation and discussion of productivity and the relationship with capital and labour (and intermediate inputs) for 380 classes of private business in Australia. Our classes are defined by 19 industry sectors, 4 age classes of firm, and 5 size classes of firm. The data is grouped by these 380 classes of firm and in its totality it covers 954,367 private businesses in Australia for the tax year 2014-15. The data is derived from Australian tax records submitted by each individual company and aggregated up to the 380 classes. In a sense, we are considering the 'average' firm within each of our 380 classes. For ease of presentation, we present the sample statistics for our key variables of interest at the firm level by dividing the total class figures by the number of firms within that class of firms. These are reported in Table 1. 
Table 1: Sample statistics: Within Class Firm Average (AUD \$m)

\begin{tabular}{|l|l|l|l|l|}
\hline Variable & Mean & Std Dev & Min & Max \\
\hline Total Income & 7.298 & 9.924 & -0.011 & 38.800 \\
\hline Total Expenses & 7.170 & 10.600 & 0.000 & 84.800 \\
\hline Cost of & 2.782 & 4.503 & 0.000 & 21.800 \\
\hline Intermediate & & & & \\
\hline Wages/Salaries & 1.268 & 1.949 & 0.000 & \\
\hline Interest Paid & 0.153 & 0.531 & 0.000 & 13.200 \\
\hline All other & 2.824 & 4.234 & 0.000 & 7.208 \\
\hline expenses & & & 52.400 \\
\hline Profit/Loss & 0.128 & 3.694 & 55.900 & 31.600 \\
\hline Total Assets & 12.900 & 35.100 & 0.000 & \\
\hline Value Added & 4.517 & 6.377 & -0.118 & \\
\hline
\end{tabular}

From Table 1 we can observe that the average firm recorded total income of AUD\$7.3m with total operating expenses of AUD\$7.2m and generated a modest profit of AUD\$128,000. Wages and Salaries were AUD\$1.27m and intermediate goods and services amounted to AUD\$2.8m. Total assets employed were AUD\$12.9m. Value added was AUD\$4.5m. As can be observed from the minimum and maximum figures there is tremendous variation across firms' reflecting the size, age, and industry structure of the total business population in the Australian economy. The industry sector with the largest average total income per firm was D: Electricity, Gas, Water, and Waste at AUD\$8.76m and the smallest average firm income was in O: Public Administration and Safety at AUD\$6.05m. The most profitable industry, on average, was K: Financial and Insurance Services with 
profits of AUD\$2.62m, and the least profitable was B: Mining which had average per firm losses of AUD\$5.89m.

Our starting point in terms of estimation was the Cobb-Douglas production function. This was expressed in log linear form and modelled by OLS. The functional form can be written as;

$$
Y_{i}=A L_{i}^{\alpha} K_{i}^{1-\alpha},
$$

Where $Y=$ output, $L=$ quantity of labour, and $K=$ quantity of capital. Here, as we do not have the actual number of employees, we use the total wage and salary bill for our labour measurement. The $A$ and $\alpha$ are parameters. In addition to this basic function, one important property is the assumption that the marginal rate of substitution (the amount by which the quantity of one input, say capital, has to be reduced when one extra unit of the other input, say labour, is used, to hold output constant) between labour and capital is 1 . We tested for the alternative CES specification and after empirical testing rejected this model in favour of Cobb-Douglas (see End note).

The first model to be estimated is Cobb-Douglas and can be written as;

$$
\log Y_{i}=\log A+\alpha \log \text { Capital }+b \log \text { Labour }+e_{i}
$$

Our reference model generates the following estimates:

$$
\mathrm{Y}=4.035[8.86]+0.125 K[3.01]+0.797 \mathrm{~L}[13.94]
$$

F-stat $=736.38$

Using this Cobb-Douglas specification we can estimate the corresponding $\delta$, the distributional shares for capital and labour, and v, the returns-to-scale parameter. Here the distributional shares for capital is 0.136 and labour 0.864 . The $v$ is estimated to be 0.922 which implies decreasing returns-toscale. 


\section{Main Results}

We augmented the basic estimating equation to include 4 firm age classes and 19 industry sector groupings (Model 1 Table 2). Regarding firm age class we find that value added follows an inverted ' $U$ ' shaped with the youngest ( $0-2$ years) and oldest (10 years or more) firms being less productive than 3-9 year old firms. This suggests that once firms have survived the initial start-up period they are finding it less difficult to be productive. Only when they are ten years or older does productivity drop off. This is an intriguing finding which merits further research and may relate to relative access to resources, managerial capabilities, and incumbent competition.

Setting agriculture, forestry, and fishing as our reference industry sector to zero, Fig.1 reports the respective coefficients from our production function. The most productive industry sector is K: Financial and Insurance Services. Other relatively productive industry sectors include A: Agriculture, Forestry, Fishing, L: Rental, Hiring, Real Estate, I: Transport, Postal, Warehousing, and, E: Construction. The least productive industry sectors are B: Mining, N: Administrative and Support Services, C: Manufacturing, O: Public Administration and Safety, and, S: Other Services. 
Fig.4: Industry sector coefficients (reference group = A: Agriculture, Forestry and Fishing)

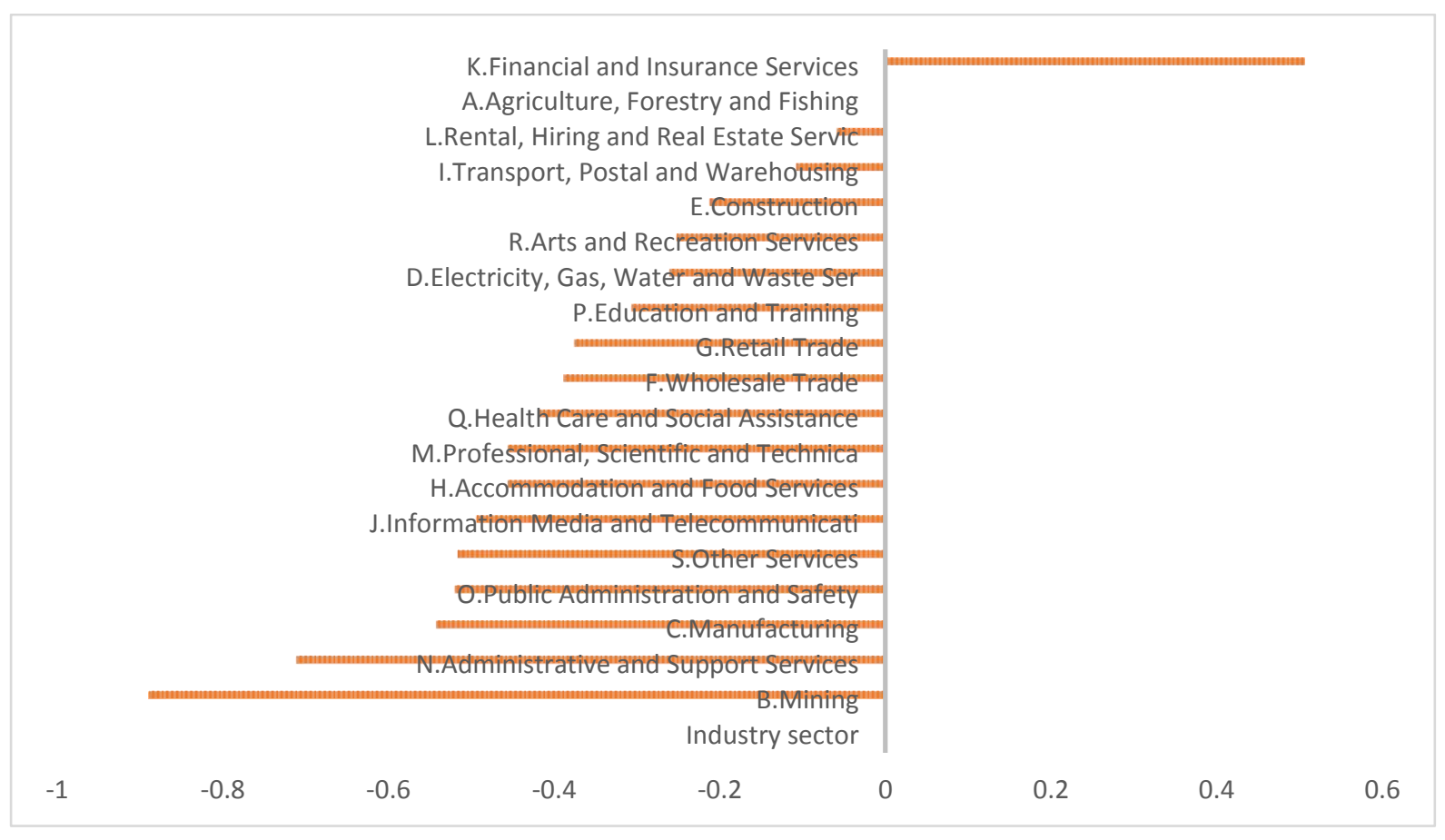

Next we explored whether there were differences across the absolute value added distribution both in terms of the relative contributions' of capital and labour, but also in terms of returns-to-scale.

These results are reported in Models 2-4, Table 2. It is apparent that the contribution of capital to production is increasing as we move from the .25 percentile through to the .75 percentile. Equally, the contribution of labour is diminishing. The relative distributional shares, $\delta$, are calculated to be 0.06 for capital at the .25 percentile, 0.08 at the .50 percentile, and 0.25 at the .75 percentile.

Conversely, the relative distributional share for labour $(1-\delta)$ is $0.94,0.92$, and 0.75 respectively as we move from the .25 percentile through to the .75 percentile. These broad findings may suggest that low value added creating firms might be constrained in capital markets. In terms of returns-toscale, $v$, the respective estimates are $0.973,0.956$, and, 0.971 as we move from the .25 to .75 percentile of the distribution, all of which imply decreasing returns. 
Next we split our sample into firms that made a positive total profit and those that made a total loss (Model 5-6, Table 2). Here $66.58 \%$ of firms made a total profit and $33.42 \%$ made a loss. Here we find that in loss making firms the contribution of capital is higher than in profit making firms. The relative distributional shares for capital are 0.06 in profitable firms and 0.18 in loss making firms. Both profit and loss making firms face constant returns to scale, $v=0.984$ and $v=1.018$, although loss making firms are nearer to the increasing returns to scale region $(v>1)$. These results imply that there are, on average, no productivity gains to be achieved by expanding the quantity of inputs to the production process for profitable firms, although there may be some gains to be made for a group of loss making firms.

\subsection{Age and size class effects}

Firm size (Models 7-9, Table 3) and age classes are considered next (Models 10-13, Table 4). We might a priori expect that younger and smaller firms organise their production in different ways to older and larger firms with more established markets and greater access to resources and factor inputs (capital and labour). On firm size class, we observe that the relative distributional share of capital, $\delta$, is largest at 0.215 for large firms and smallest at 0.039 for medium-sized firms. These findings may imply that capital constraints are more of an issue for SMEs than large firms. Both small and large firms face decreasing returns-to-scale, but medium-sized firms face constant returns. This may reflect the nature of the output markets each size class of firm faces, both in a spatial context and in terms of the relative competitiveness of the market structure. On firm age class, we find that the distributional share of capital is lower for younger firms (0-5 years) and increases significantly for older age classes of firm and peaks for well-established firms (10 years plus) at 0.196. Regarding returns-to-scale, we find that the youngest firms (0-2 years) face decreasing returns, but more stablished age classes (3-9 years) face constant returns-to-scale. The very oldest firms face decreasing returns, implying that productivity approximates an inverted ' $U$ ' shape in age class of 
firm. This former result may reflect the fixed capability of the founding entrepreneur and her capability to organise production.

\subsection{State of technology}

Here we consider age and size class effects in respect of 'state of technology' effects (the A parameter in the production function). This captures elements of technology adoption, but also a firms understanding of the prevailing technology.

Fig 5: Age and size class effects on the 'state of technology'

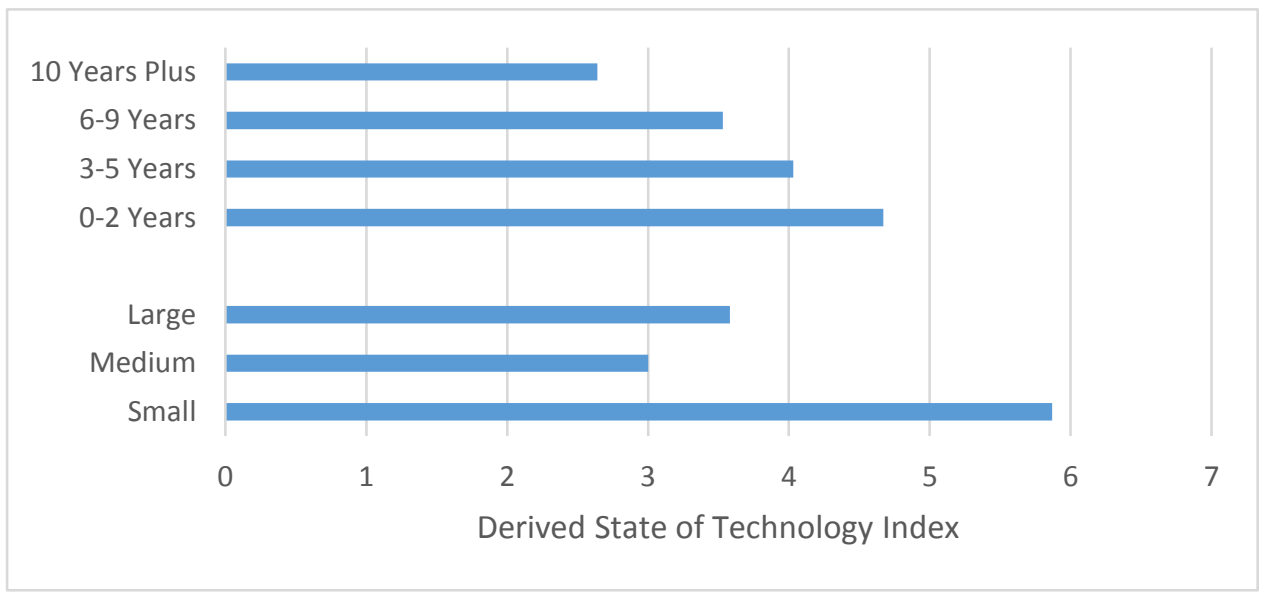

There are several interesting features apparent in our estimates of the state of technology. In respect of firm age classes, we find that there is a negative relationship between firm age class and the state of technology. In short, the younger a firm is, the less technological constraints, on average, it faces. This means that the very oldest firms in the economy, on average, have the most significant constraints in terms of the technology they use, or their understanding of the prevailing state of technology. We also observe that there are differences apparent across firm size classes. But it is not a linear relationship. Here small firms face the lowest technological constraints, mediumsized firms the highest, and large firms lie above medium-sized firms, but significantly below small 
firms. These findings are particularly interesting in a world where the speed of change in prevailing technologies is rapid.

Table 5: Summary of hypotheses and results

\begin{tabular}{|c|c|}
\hline Hypothesis & Empirical Results \\
\hline $\begin{array}{l}\text { H1: Younger classes of firm will exhibit } \\
\text { increasing returns-to-scale as they gain market } \\
\text { share from older firms and seek to move } \\
\text { towards the MES (minimum efficient scale) of } \\
\text { production }\end{array}$ & $\begin{array}{l}\text { Partially Rejected. Returns-to-scale across age } \\
\text { classes of firms approximate an inverted ' } U \text { ' } \\
\text { shape which implies that businesses between } 3 \\
\text { and } 9 \text { years old are the most efficient age } \\
\text { classes. }\end{array}$ \\
\hline $\begin{array}{l}\text { H2: Productivity is increasing in size class of } \\
\text { business }\end{array}$ & $\begin{array}{l}\text { Partially Rejected. Returns-to-scale across size } \\
\text { classes of firms approximate an inverted ' } U \text { ' } \\
\text { shape which implies that medium-sized } \\
\text { businesses are the most efficient age classes. }\end{array}$ \\
\hline $\begin{array}{l}\text { H3: There will be a negative relationship } \\
\text { between the prevailing 'state of technology' } \\
\text { and firm size and age classes }\end{array}$ & $\begin{array}{l}\text { Accepted for age classes. The 'state of } \\
\text { technology' diminishes in firm age class. } \\
\text { Partially rejected for size classes. The 'state of } \\
\text { technology is highest in small businesses and } \\
\text { lowest amongst medium-sized businesses. }\end{array}$ \\
\hline $\begin{array}{l}\text { H4: Smaller (larger) classes of firm will adopt } \\
\text { more labour (capital) intensive modes of } \\
\text { production }\end{array}$ & $\begin{array}{l}\text { Accepted. There is a distinct shift from labour } \\
\text { intensive modes of production in small size } \\
\text { classes of firm to capital intensive modes in } \\
\text { larger sized classes of firm. }\end{array}$ \\
\hline
\end{tabular}


Table 5 summarise our results against our starting hypotheses. We partially reject $\mathrm{H} 1$ as business age classes that have moved beyond the start-up phase are the most productive. But equally, very well established firms are relatively unproductive. Again, we partially reject $\mathrm{H} 2$ as medium-sized firms are the most efficient size class, but small and large businesses are less productive. Our results are partially in support of $\mathrm{H} 3$ which relates youth and to some degree smallness to the adoption and understanding of the prevailing technology. This suggests that small and younger businesses are well placed to take advantage of new production technologies as they appear. The evidence on modes of production, $\mathrm{H} 4$, is very clear in that smaller and younger firms adopt more labour intensive modes of production and there is a shift towards greater capital intensity as firms' age and become larger. This might imply that smaller and younger firms are constrained in capital markets.

Our overarching research question was: Is it the case, as theory predicts, that smaller and younger firms should be disadvantaged due to their scale and youth in creating value added? Our evidence suggests that this is not necessarily the case. For start-ups and small businesses in general, there is an issue around productivity when compared to their peers who have moved beyond the start-up stage and/or grown into medium-sized businesses. But this is also true for very old and large businesses. But the superior ability of younger and smaller businesses to deal with technology adoption means that they have a relative advantage in the creation of value added over older and larger firms. There is a productivity issue around capital investment and a more balanced mix of capital and labour, but the answer may lie in the functioning of capital markets and how they deal with lending and equity investment in new and small firms. 


\section{Conclusions}

We have estimated a series of production functions in order to understand more about how production is organised in the Australian private business sector and how much this varies across different types of business. It is immediately apparent that there is huge variation in productivity across different industry sectors. This might reflect substantial differences in the competitive structure of markets, international orientation and exposure to foreign competition, as well as the evolution of consumer demand for the output of different industry sectors. We find an interesting pattern in firm age classes with an inverted ' $U$ ' shaped productivity effect identified as the youngest and oldest firms being relatively less productive. This might reflect liability of newness effects as firms at the early stage of their life-cycles struggle with the complexity of managing operations and learning to adjust to operating in markets where established competitors have begun to take notice of them and respond.

The relative importance of capital in production also generated some interesting results with the distributional share of capital (relative to labour) increasing as we move across the value added distribution. This may reflect not only the capital market constraints that some firms face, but also the ability of labour to create value from capital and this relates to the relative quality of labour (the ability of a worker to operate a machine effectively). Our use of the wage bill to capture labours contribution should address this quality issue, but only if workers' pay approximates their marginal product (i.e more productive workers get paid more). And there is a strong theoretical and empirical evidence base to suggest that this might not be the case. But our argument here is strengthened by our equivalent findings in relation to capital becoming increasingly important in the determination of output as firms move through their life-cycles. Here, as firms learn-by-doing, capital use gradually becomes more efficient. But loss-making firms tend to have a higher relative share of capital to 
labour than profitable firms, suggesting that it is quality of labour constraints that are problematic for them.

Finally, and this certainly merits further research, the general finding that most, but not all, size-ageindustry classes of firm face decreasing returns-to-scale suggests that more creative thinking is required if Australian businesses are to generate the sustained levels of productivity improvements that will raise the future incomes and wealth of the population. Our results suggest that labour market and skills issues might be a good starting point, and this includes entrepreneurs, managers, and workers, but it is likely that the answer is much more complex and multi-faceted.

\section{Policy implications}

Our evidence suggests several potential issues for policy deliberation. Firstly, we note that capital intensive modes of production tended to be associated with the creation of more value added. But we also found that smaller size classes of business tended to adopt labour intensive production techniques. This may be indicative of capital constraints which restrict the funds available to smaller businesses to invest in physical capital. Throughout the world policy-makers have been very active in this area both in the form of loan guarantees on the debt side and hybrid venture capital schemes on the equity side. Australia in unusual in that it has been notably inactive on both.

The broad body of evidence suggests that most classes of firm face decreasing returns-to-scale. This might imply that businesses need to upgrade their softer managerial skills to facilitate smarter working at their current scale rather than focusing on growth. But smaller firms appear to be at a relative advantage in the adoption and understanding of technology which suggests that their technical skills might be superior. In this sense policy might consider a programme of business skills development for smaller businesses. 
The scale of industry sector variations in the ability to create value from a given endowment of resources is large. On a positive note, knowledge intensive service sectors are highly productive, particular amongst dynamic young classes of business. But more traditional sectors, particularly mining, are very unproductive, particularly amongst smaller size classes of business. This might suggest on the medium to long-term that the economy might benefit from a reallocation of its productive resources away from traditional industries towards more value creating, knowledge based service sectors.

\section{Study limitations and further research}

We have made the first step towards understanding productivity and value creation in the most successful global economy of the last two decades. We found that many of the theoretical predictions about smaller and younger businesses do not stand up against the evidence. This leaves us with a research gap in the sense that we need to understand more about the internal dynamics of smaller and younger businesses to identify precisely how they run their businesses and what strategies they use to successfully compete against established and often larger firms. This requires more detailed firm level data to link with, and augment, the basic production function parameters. 


\section{References}

Acs, Z. J., \& Mueller, P. (2008). Employment effects of business dynamics: Mice, gazelles and elephants. Small Business Economics, 30(1), 85-100.

Acs, Z. J. (1992). Small business economics: A global perspective. Challenge, 35(6), 38-44.

Alvarez, R., \& Crespi, G. (2003). Determinants of technical efficiency in small firms. Small Business Economics, 20(3), 233-244.

Antonelli, C., Crespi, F., \& Scellato, G. (2015). Productivity growth persistence: firm strategies, size and system properties. Small Business Economics, 45(1), 129-147.

Arkolakis, C., Papageorgiou, T., \& Timoshenko, O. (2015). Firm learning and growth (No. 2015-5).

Atkinson, J., \& Storey, D. J. (Eds.). (2016). Employment, the small firm and the labour market. Routledge.

Barteisman, E., Scarpetta, S., \& Schivardi, F. (2005). Comparative analysis of firm demographics and survival: evidence from micro-level sources in OECD countries. Industrial \& Corporate Change, 14(3).

Bento, P., \& Restuccia, D. (2016). Misallocation, establishment size, and productivity (No. w22809). National Bureau of Economic Research.

Beugelsdijk, S., Klasing, M. J., \& Milionis, P. (2017). Regional economic development in Europe: the role of total factor productivity. Regional Studies, 1-16.

Blinder, A. S. (1987). Credit rationing and effective supply failures. The Economic Journal, 97(386), 327-352.

Bloom, N., \& Van Reenen, J. (2006). Management Practices, Work-L ife Balance, and Productivity: A Review of Some Recent Evidence. Oxford Review of Economic Policy, 22(4), 457-482. 
Boone, T., Ganeshan, R., \& Hicks, R. L. (2008). Learning and knowledge depreciation in professional services. Management Science, 54(7), 1231-1236.

Brown, C., Hamilton, J., \& Medoff, J. L. (1990). Employers large and small. Harvard University Press.

Coad, A., Daunfeldt, S. O., Hölzl, W., Johansson, D., \& Nightingale, P. (2014). High-growth firms: introduction to the special section. Industrial and Corporate Change, 23(1), 91-112.

Coco, G. (2000). On the use of collateral. Journal of Economic Surveys, 14(2), 191-214.

Chow, C. K. W., \& Fung, M. K. Y. (1997). Firm size and performance of manufacturing enterprises in PR China: The case of Shanghai's manufacturing industries. Small Business Economics, 9(3), 287-298.

Cowling, M. (2003). Productivity and corporate governance in smaller firms. Small Business Economics, 20(4), 335-344.

Cowling, M. (2010). The role of loan guarantee schemes in alleviating credit rationing in the UK. Journal of Financial Stability, 6(1), 36-44.

Evans, D. S. (1987). Tests of alternative theories of firm growth. Journal of Political Economy, 95(4), 657-674.

Evans, D. S., \& Jovanovic, B. (1989). An estimated model of entrepreneurial choice under liquidity constraints. Journal of Political Economy, 97(4), 808-827.

Freel, M. S. (2005). Patterns of innovation and skills in small firms. Technovation, 25(2), 123-134.

Gopinath, G., Kalemli-Özcan, Ş., Karabarbounis, L., \& Villegas-Sanchez, C. (2017). Capital allocation and productivity in South Europe. The Quarterly Journal of Economics, 132(4), 1915-1967.

Haltiwanger, J., Jarmin, R. S., \& Miranda, J. (2013). Who creates jobs? Small versus large versus young. Review of Economics and Statistics, 95(2), 347-361. 
Hsieh, C. T., \& Klenow, P. J. (2009). Misallocation and manufacturing TFP in China and India. The Quarterly Journal of Economics, 124(4), 1403-1448.

İmrohoroğlu, A., \& Tüzel, Ş. (2014). Firm-level productivity, risk, and return. Management Science, 60(8), 2073-2090.

Jovanovic, B. (1982). Selection and the Evolution of Industry. Econometrica: Journal of the Econometric Society, 649-670.

León-Ledesma, M. A., McAdam, P., \& Willman, A. (2015). Production technology estimates and balanced growth. Oxford Bulletin of Economics and Statistics, 77(1), 40-65.

Li, Y., \& Rama, M. (2015). Firm Dynamics, Productivity Growth, and Job Creation in Developing Countries: The Role of Micro-and Small Enterprises. The World Bank Research Observer, 30(1), 3-38.

Li, G., \& Rajagopalan, S. (1998). A learning curve model with knowledge depreciation. European Journal of Operational Research, 105(1), 143-154.

Montresor, S., \& Vezzani, A. (2015). The production function of top R\&D investors: Accounting for size and sector heterogeneity with quantile estimations. Research Policy, 44(2), 381-393.

Neumark, D., Wall, B., \& Zhang, J. (2011). Do small businesses create more jobs? New evidence for the United States from the National Establishment Time Series. The Review of Economics and Statistics, 93(1), 16-29.

Nickell, S. J. (1996). Competition and corporate performance. Journal of Political Economy, 104(4), 724-746.

Parker, S. C., \& Van Praag, C. M. (2006). Schooling, capital constraints, and entrepreneurial performance: The endogenous triangle. Journal of Business \& Economic Statistics, 24(4), 416-431. Pozzi, A., \& Schivardi, F. (2016). Demand or productivity: What determines firm growth? The RAND Journal of Economics, 47(3), 608-630. 
Raymond, W., Mairesse, J., Mohnen, P., \& Palm, F. (2015). Dynamic models of R \& D, innovation and productivity: Panel data evidence for Dutch and French manufacturing. European Economic Review, $78,285-306$.

Siepel, J., Cowling, M., \& Coad, A. (2017). Non-founder human capital and the long-run growth and survival of high-tech ventures. Technovation, 59, 34-43.

Stiglitz, J. E., \& Weiss, A. (1981). Credit rationing in markets with imperfect information. The American Economic Review, 71(3), 393-410.

Syverson, C. (2004). Market structure and productivity: A concrete example. Journal of Political Economy, 112(6), 1181-1222.

Syverson, C. (2011). What determines productivity? Journal of Economic Literature, 49(2), 326-365. Wang, Y. L. (2010). Does collateral cause inefficient resource allocation? Journal of Economics and Business, 62(3), 220-233.

Wadhwani, S., \& Wall, M. (1990). The effects of profit-sharing on employment, wages, stock returns and productivity: Evidence from UK micro-data. The Economic Journal, 100(399), 1-17.

End notes:

The CES is an alternative specification of the production function which does not have this property relating to the marginal rate of substitution. Having an underlying non-linear form, the CES can be expressed as;

$Y_{i}=\gamma\left[\delta K_{i}^{-\rho}+(1-\delta) L_{i}^{-\rho}\right]^{-v / \rho} e^{\varepsilon i}$,

Here, $p>0,1>\delta>0, v>0, \rho>-1$. These four parameters of the function, $\gamma, \delta, v$, and $\rho$, are taken to represent efficiency, distributional shares, returns-to-scale, and factor substitution. In our modelling, it is fundamental in our choice of production function whether or not the $\rho$ parameter, relating to factor substitution, is statistically not different from zero, which would imply that there is an 
elasticity of substitution of 1 (from 1/1- $\rho$ ). If this was found to be the case then the CES function collapses to the Cobb-Douglas form.

The CES model can be written thus, $\log Y_{i}=\log \alpha-v / \rho \log \left[\delta\right.$ Capital $_{i}^{-\rho}+(1-\delta)$ Labour $\left._{i}^{-\rho}\right]+e_{i}$. Testing for the most appropriate functional form, Cobb-Douglas or CES, is important before we begin to develop our full modelling strategy. The focus of interest is on the $\rho$ parameter. If $\rho$ is statistically not different from zero then this would support rejection of CES in favour of the Cobb-Douglas functional form as it implies an elasticity of substitution of 1 . If we consider a Taylor series expansion of the CES function (i.e expand $\log Y$ around $\rho=0$ ), then we can generate an equation that can be estimated thus;

$\log Y_{i}=\log v+v \delta \log K_{i}+v(1-\delta) \log L_{i}-1 / 2 \rho v \delta(1-v)\left[\log K_{i}-\log L_{i}\right]^{2}+\varepsilon_{i}$

Here, the first element is the Cobb-Douglas model and the second element allows for $\rho$ to have a non-zero value. Again, if $\rho=0$ then Cobb-Douglas is favoured over CES. We can derive an unrestricted linear form;

$$
\log Y_{i}=b_{1}+b_{2} \log K_{i}+b_{3} L_{i}+b_{4}\left[\log K_{i}-\log L_{i}\right]^{2}+\varepsilon i
$$

The relevant parameter here is the estimate of $\beta_{4}$ which determines whether we can reject the CES specification. Here if $\beta_{4}$ is statistically zero then Cobb-Douglas is the most appropriate functional form. The first finding from the unrestricted CES estimate is that our key parameter of interest, $\beta 4$, is not statistically significant (Test $\left(\left[\operatorname{logK}-\log L^{2}\right]=0, F=0.13, \operatorname{Pr}>F 0.723\right)$. The estimating equation can be used to derive the parameters of Equation (5) as follows;

$$
\delta=\beta 2 / \beta 2+\beta 3=0.095 / 0.921=0.103
$$

The $\delta$ corresponds to the distributional shares between capital and labour, hence the relative shares are 0.103 for capital and 0.897 for labour.

$v=\beta 2+\beta 3=0.921$ 
As $v$ is significantly less than 1 , this implies decreasing returns-to-scale (Test $\ln K+\ln L=1, F=8.49$, Prob $>F=0.0039)$.

$\rho=-2 \beta_{4}\left(\beta_{2+} \beta_{3}\right) / \beta 2+\beta 3=-2 * 0(0.921) / 0.078=0$

The $\rho$ is the substitution parameter, and the marginal rate of substitution is calculated to be 1 using 1/1- $\rho$. Even if we allow for it to be non-zero then we get an estimated MRS of $1 /(1-0.006)=0.994$.

Table A: Cobb-Douglas and CES estimates for value added

\begin{tabular}{|c|c|c|c|c|c|}
\hline \multicolumn{3}{|c|}{ Cobb-Douglas } & \multicolumn{3}{|l|}{ CES } \\
\hline \multicolumn{3}{|c|}{ Dependent variable $=$ Value Added } & \multicolumn{3}{|c|}{ Dependent variable $=$ Value Added } \\
\hline Parameter & Coefficient & T stat & Parameter & Coefficient & T stat \\
\hline A (constant) & 4.035 & 8.86 & $\beta 1$ (constant) & 4.085 & 8.92 \\
\hline$\alpha$ (capital) & 0.125 & 3.01 & $\beta 2$ (capital) & 0.095 & 1.32 \\
\hline \multirow[t]{2}{*}{$\beta$ (labour) } & 0.797 & 13.54 & $\beta 3$ (labour) & 0.826 & 10.02 \\
\hline & & & $\beta 4\left(\left[\log K-\log L^{2}\right]\right)$ & 0.006 & 0.35 \\
\hline F stat & 736.38 & & 717.89 & & \\
\hline
\end{tabular}


Table 2: Value Added Production Function Models

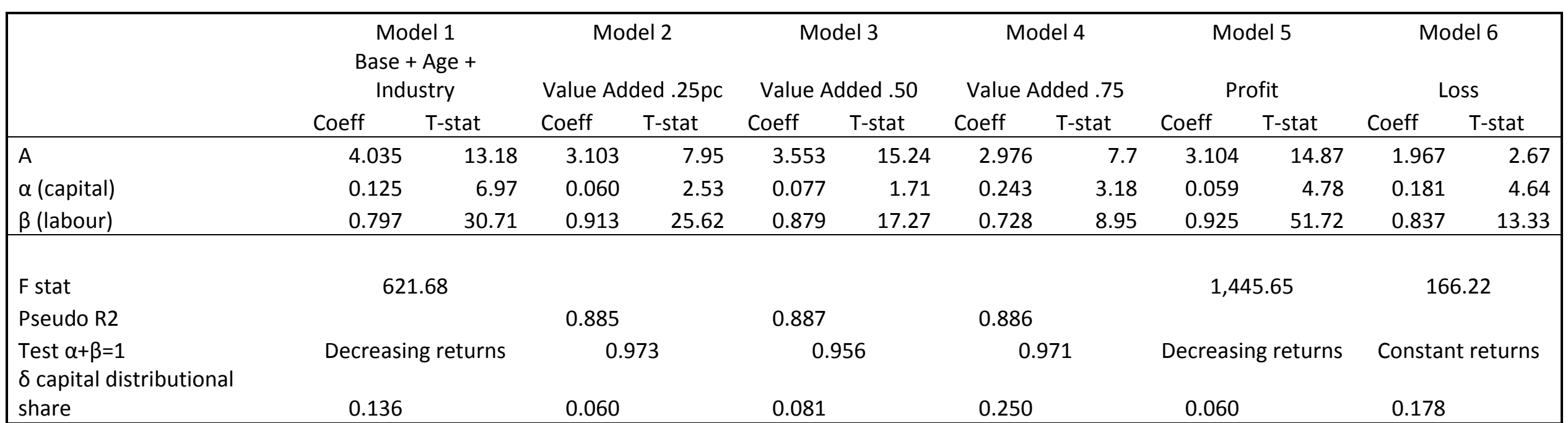


Table 3: Value Added Production Function Models (Firm Size Class)

\begin{tabular}{|c|c|c|c|c|c|c|}
\hline & \multicolumn{2}{|c|}{$\begin{array}{c}\text { Model } 7 \\
\text { Small Firm }\end{array}$} & \multicolumn{2}{|c|}{$\begin{array}{c}\text { Model } 8 \\
\text { Medium Firm }\end{array}$} & \multicolumn{2}{|c|}{$\begin{array}{c}\text { Model } 9 \\
\text { Large Firm }\end{array}$} \\
\hline & Coeff & T-stat & Coeff & T-stat & Coeff & T-stat \\
\hline$A$ & 5.874 & 9.24 & 3.002 & 5.3 & 3.577 & 8.36 \\
\hline$\alpha$ (capital) & 0.070 & 1.93 & 0.039 & 2.85 & 0.198 & 6.68 \\
\hline$\beta$ (labour) & 0.754 & 15.15 & 0.952 & 28.39 & 0.735 & 20.94 \\
\hline F stat & 72.27 & & 85.64 & & 232.45 & \\
\hline $\begin{array}{l}\text { Test } \alpha+\beta=1 \\
\delta \text { capital distributional } \\
\text { share }\end{array}$ & \multicolumn{2}{|c|}{ Decreasing returns } & \multicolumn{2}{|c|}{ Constant returns } & \multicolumn{2}{|c|}{ Decreasing returns } \\
\hline
\end{tabular}


Table 4: Value Added Production Function Models (Firm Age Class)

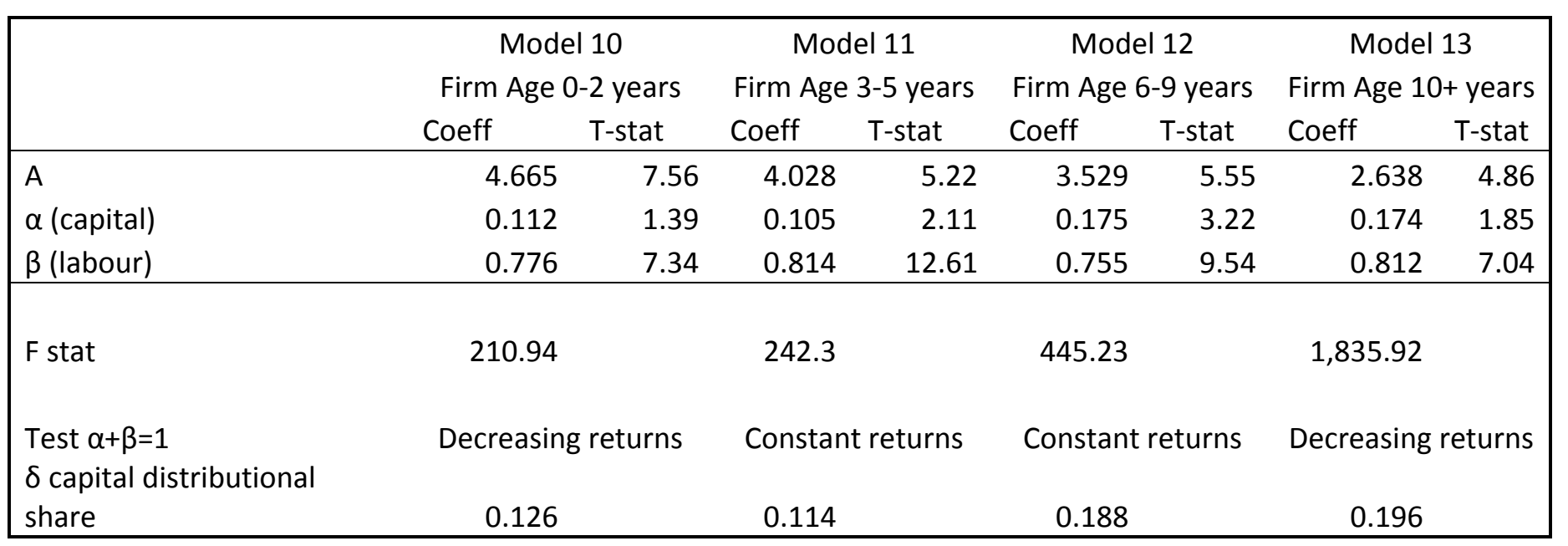

